\title{
Dental materials and their performance for the management of screw access channels in implant-supported restorations
}

\author{
Philipp RAAB, Christos ALAMANOS, Sebastian HAHNEL, Dimitrios PAPAVASILEIOU, Michael BEHR \\ and Martin ROSENTRITT
}

\author{
Department of Prosthetic Dentistry, Regensburg University Medical Center, Regensburg, Germany
}

Corresponding author, Philipp RAAB; E-mail:dr.raab@praxis-oppenberg.de

\begin{abstract}
Unsuccessfully sealed screw access channels of prosthetic implant abutments may lead to malodor or peri-implant diseases in gingival tissues adjacent to implant-supported restorations. Therefore, 72 sets of screw channel analogs with six different materials incorporated (Polytetrafluoroethylene (PTFE), wax, gutta-percha, cavit, endofrost-pellets and cotton pellets) were exposed (2.5 h, $37^{\circ} \mathrm{C}$ ) to Streptococcus mutans, oralis and Candida albicans suspensions. Bacterial adherence was quantified by using the fluorescence dye, Alamar Blue/resazurin, and an automated multifunctional reader. For quantification of fungal adherence the ATP-based bioluminescence approach was used. High relative fluorescence and luminescence intensities $(>10,000)$, indicating high adhesion of streptococci and fungi were found for cotton and endofrost-pellets and low intensities $(<5,000)$ for wax, gutta-percha, cavit and PTFE. The quantity of bacterial and fungal adhesion differed significantly between the assessed various sealing materials. In conclusion and within the limitations of this study, wax, gutta-percha, cavit and PTFE should be preferred as sealing materials.
\end{abstract}

Keywords: Screw access channel, Implant, Bacteria, Candida, Peri-implantitis

\section{INTRODUCTION}

To date, the microbiological effect of managing screw access channels of implant abutments prior to cementation or hybrid abutment crowns has not been investigated in detail. However, there are several described methods for closing and sealing the opening of screw access channels, without any evidence-based data $^{1-3)}$. The technique selected for filling screw access channels depends upon the personal preference of the dentist and may influence abutment crown retention ${ }^{1,4,5}$. Multiple studies have shown that bacterial colonization of the implant-abutment interface and the internal implant cavity is an important factor in the etiology and pathogenesis of peri-implant inflammation and marginal bone $\operatorname{loss}^{6-14)}$. In two-piece dental implant systems, progressive colonization of periodontopathogenic bacteria has been found in the space between implant components that was associated with inflammation of the peri-implant soft tissue and peri-implant bone loss ${ }^{15}$. Two-component implant systems also present gaps at the implant-abutment connection and the screw access hole, providing a reservoir and channel for bacterial colonization ${ }^{9,12,15)}$. Up to now, studies have only focused on the technique, esthetic outcome, and effect on the retention of suprastructures and only one study has compared biological aspects of different screw hole filling materials ${ }^{2-4,16,17)}$.

The progressive colonization of the internal implant cavity and the screw access channel by mostly anaerobic proteolytic microorganisms, which also produce malodor, leads to the formation of a bacterial

Color figures can be viewed in the online issue, which is available at J-STAGE.

Received Feb 2, 2016: Accepted Sep 1, 2016

doi:10.4012/dmj.2016-049 JOI JST.JSTAGE/dmj/2016-049 reservoir8,18-20). Malodor - usually caused by the presence of gram-negative oral bacteria - is the result of microbial metabolism of amino acids in the oral cavity $^{21,22)}$. Streptococci and other gram-positive oral bacteria may also lead to malodor due to the production of a volatile sulfur compound (VSC) ${ }^{23,24)}$. The fungal pathogen Candida albicans is a commensal fungal species that commonly colonizes the surfaces of the oral cavity and the dentures ${ }^{25}$. Candida albicans is widely present in denture plaque and may also lead to halitosis ${ }^{26,27)}$. Different materials such as PTFE, wax, gutta-percha, temporary restorative fillings, composite resin, polyvinyl siloxane (PVS), and auto-polymerizing acrylic resin are used for filling the screw access holes of abutments. However, most dentists prefer endofrost pellets and cotton pellets because of their easier retrievability ${ }^{1-3,5,16)}$. If a screw-retained restoration is selected, insufficiently sealed screw channels may lead to malodor and peri-implant inflammation due to bacteria or fungal adhesion and entrapment of food particles in the opening of screw access channels. The implant-abutment interface as an anaerobic condition is also an important factor in the development of oral malodor ${ }^{27}$. Up to last year, no evidence was available for induction of peri-implant mucositis or peri-implantitis by internal bacterial contamination. However, some studies have shown internal bacterial infiltration of the implant cavity from an external source and vice versa $^{10,28,29)}$. Contamination can be caused by external bacteria trapped during prosthetic placement or as a result of leakage at the implant-abutment interface (Fig. 1) ${ }^{11}$. A recent study has proved the relationship between internal colonization with periodontopathogenic bacteria and peri-implant bone $\operatorname{loss}^{15}$. 
Thus, materials for screw channel sealing should have low susceptibility to microbial adhesion. The hypothesis of this investigation was that the different materials available for sealing screw access channels do not differ in their susceptibility to bacterial or fungal adhesion. Therefore, we investigated the in vitro colonization of Streptococcus oralis, Streptococcus mutans, and Candida albicans on six standard sealing materials (Polytetrafluoroethylene (PTFE), wax, guttapercha, cavit, endo-frost pellets, and cotton pellets).

\section{MATERIALS AND METHODS}

Six commercially available and widely used materials for filling screw access channels were investigated (Table 1). The materials were either recommended by the dental implant manufacturer or have been recently described for this application in the literature ${ }^{1)}$. Six

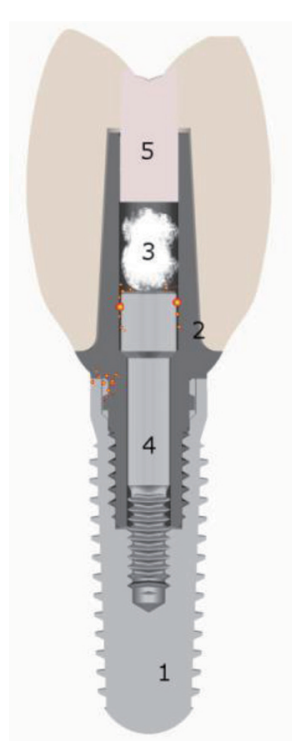

Fig. 1 Cross section of inner implant-cavity: red points indicate ways of bacterial infiltration from an external source and vice versa.

(1) Implant root fixture (2) abutment (3) tested materials (4) internal screw (5) composite resin. screw channel analogs $(\mathrm{D}=2.0 \mathrm{~mm}, \mathrm{H}=3.0 \mathrm{~mm})$ according to Straumann (Narrow CrossFit, NC, screw channel diameter $\mathrm{D}=2.2 \mathrm{~mm}$, Straumann Manuel —Step by Step Prosthetic Procedures 2010) were drilled (diamond red, $1.5 \mathrm{~mm}$, water cooling) into a PMMA specimen holder (Fig. 2, D=10 mm, H=4 mm; Heraeus Kulzer, Germany) simulating an abutment with a sealed screw access opening under a cemented crown or a hybrid abutment crown before sealing the access opening with composite (Figs. 3 and 4). Sealing with composite was not performed to simulate consistent conditions and to guarantee a homogeneous growth of bacteria and candida. All materials were prepared according to the manufacturers' instructions, cleansed with ethanol (70\%), and incorporated in the specimen holder. An autoclave (SANOclav, WOLF, Germany) was used to sterilize all sterilizable materials and instruments at high pressure saturated steam at $121^{\circ} \mathrm{C}$ and $1 \mathrm{kgf} / \mathrm{cm}^{2}$ of pressure for $20 \mathrm{~min}^{1,30)}$. Each screw channel analog was filled with the same procedure, with the exception of the handling of the sealing material. The PTFE tape was cut into a piece with a length of $25 \mathrm{~mm}$, twisted into a spiral, filled into the screw channel analog and compacted with a sterilized plugger ${ }^{1,30)}$. The wax and gutta-percha, were cut into adequate pieces, heated over the flame of a

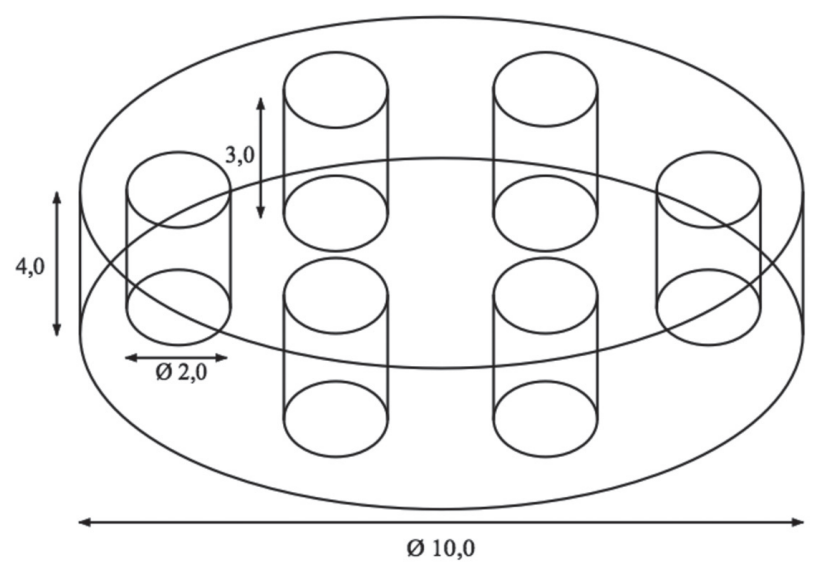

Fig. 2 Measurements of the specimen with incorporated screw channel analogs in $\mathrm{mm}$.

Table 1 Different materials used in this research

\begin{tabular}{llcc}
\hline \multicolumn{1}{c}{ Product } & Manufacturer & Sterilizable & Type \\
\hline PTFE & Cumdente & yes & Polytetrafluoroethylene \\
Wax & Kavo Kerr Group & no & Boxing Wax \\
Gutta-Percha & Coltène/Whaledent & no & ZnO, BaSO $_{4}, \mathrm{Gutta}$-percha \\
Cavit & 3M ESPE & no & ZnO, CaO \\
Endo-Frost-Pellets & Coltène/Whaledent & yes & Foam \\
Cotton-Pellets & Coltène/Whaledent & yes & Cotton \\
\hline
\end{tabular}




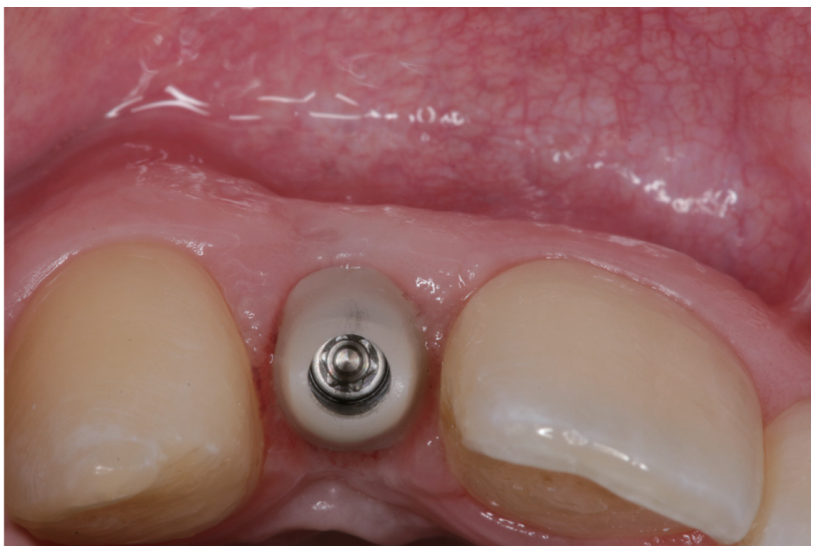

Fig. 3 Clinical situation before sealing the screw channel prior to crown cementation.

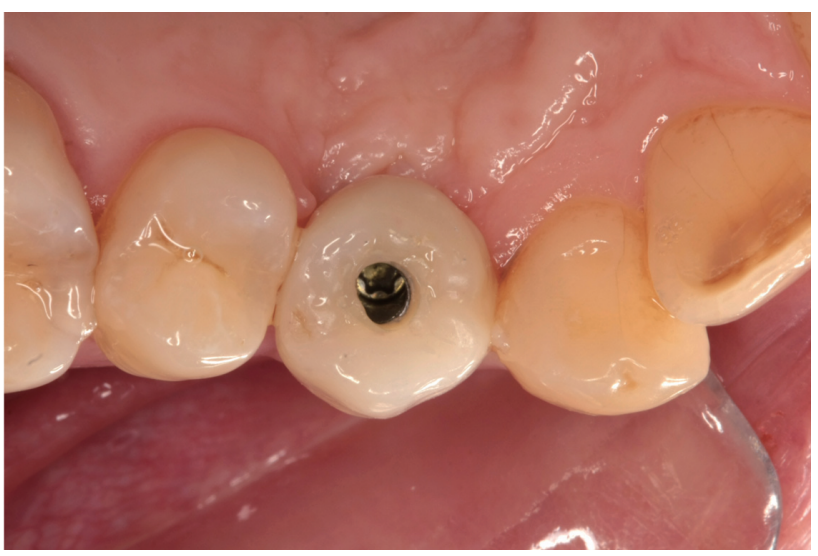

Fig. 4 Hybrid abutment crown before sealing the screw channel.

Bunsen burner for one second and afterwards condensed in the screw channel analog until completely filled ${ }^{17)}$. A required quantity of cavit paste material, endo-frost pellets and cotton pellets were filled and compacted into the screw channel analogs with a plugger.

\section{Microbial adhesion: bacteria}

Specimen holders were transferred to 24-well cell clusters (Corning, Lowell, MA, USA). The strains $S$. mutans (NCTC 10449) and S. oralis (NCTC 11427) (German Collection of Microorganisms and Cell Cultures, Braunschweig, Germany) were grown at $37^{\circ} \mathrm{C}$ in anaerobic conditions the day before the experiment and inoculated in sterile medium 92 (Trypticase Soy East Extract Medium, containing $30 \mathrm{~g}$ tryptic soy broth, Becton Dickinson Microbiology Systems, Sparks, MD, USA) and $3 \mathrm{~g}$ of yeast extract (Sigma-Aldrich, St. Louis, MO, USA). Bacteria were harvested by centrifugation $\left(2,500 \mathrm{rpm}, 18^{\circ} \mathrm{C}, 5 \mathrm{~min}\right)$, washed twice with phosphate buffered saline (PBS) (Sigma-Aldrich), and resuspended in the same buffer. The optical density of the bacterial cell suspension was set to 0.4 at $550 \mathrm{~nm}$ and controlled (spectrophotometer Genysis 10S, Thermo Spectronic Rochester, NY, USA). Each material was carefully transferred to a 48-well cell cluster and incubated with bacterial suspension (1 mL) and Resazurin (15 $\mu \mathrm{L}, 0.007536 \mathrm{~g} / 10 \mathrm{~mL}$, Resazurin, Sigma-Aldrich) using a thermo shaking device (Forma Orbital Shaker; Thermo Electron, Marietta, OH, USA) at $37^{\circ} \mathrm{C}$ for $180 \mathrm{~min}$, and carefully rinsed twice with PBS (1 mL) afterwards. Adherent bacteria were quantified by Resazurin reduction (Almar Blue) as described earlier ${ }^{31}$. Measurements were evaluated using an automated multifunctional plate reader (FLUOstar OPTIMA; BMG Labtech, Offenburg, Germany) at wavelengths of $530 \mathrm{~nm}$ excitation and $590 \mathrm{~nm}$ emission. The number of adhered bacteria cells correlates to fluorescence intensity ${ }^{32)}$.

\section{Microbial adhesion: C. albicans}

To initiate fungal adherence the materials were incubated $\left(180 \mathrm{~min}\right.$ at $\left.37^{\circ} \mathrm{C}\right)$ in C. albicans (NCTC 3255 ) suspension with an adjusted optical density of 0.4 at 540 $\mathrm{nm}$. Fungal proliferation was stimulated by incubation with a universal medium for yeast $\left(24 \mathrm{~h}\right.$ at $\left.37^{\circ} \mathrm{C}\right)$ after careful removal of the $C$. albicans suspension. The specimens were washed twice with PBS to remove nonadherent fungal cells. Adherence of $C$. albicans was quantified by means of ATP-based bioluminescence ${ }^{333}$.

\section{Statistics}

Normal distribution of data was assessed with the Kolmogorov-Smirnov test. Means and standard deviations were calculated for relative fluorescence and luminescence intensities. Statistical analysis was performed with IBM SPSS Software (v. 20.0, IBM Chicago, IL, USA) for each single microbial strain using one-way analysis of variance (ANOVA) and subsequent post-hoc analysis (Tukey test) where appropriate. The level of significance $(\alpha)$ was set to 0.05 .

\section{RESULTS}

The relative fluorescence intensities (no units) of Streptococcus oralis and mutans are presented in Fig. 5.

\section{Streptococcus oralis}

One-way ANOVA indicated significant differences in relative fluorescence intensities $(p<0.001)$. Post-hoc analysis suggested the highest relative fluorescence intensities for cotton pellets $(19,100)$ that were significantly higher than for any other material $(p<0.001)$. Endo-frost pellets showed significantly higher values than any other material except for cotton pellets $(p<0.001)$. The relative fluorescence intensities measured for the other materials did not show any significant differences $(p>0.05)$.

\section{Streptococcus mutans}

The quantity of bacterial adhesion differed significantly between the investigated materials $(p<0.001)$. Median values for $S$. mutans adhesion ranged between 3.900 and 


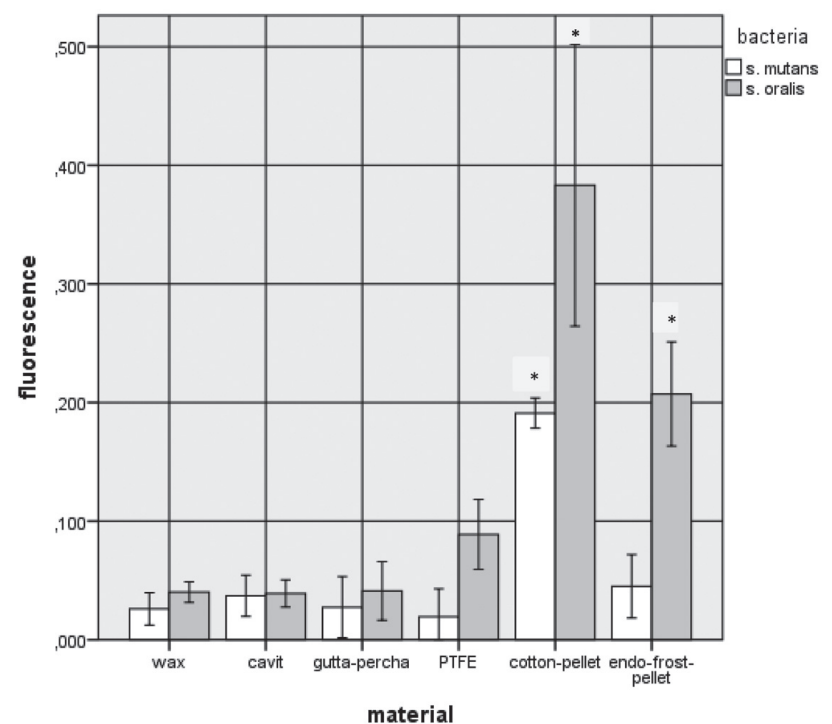

Fig. 5 Bacterial adhesion (no units) of $S$. mutans and oralis on different materials (mean, standard deviation).

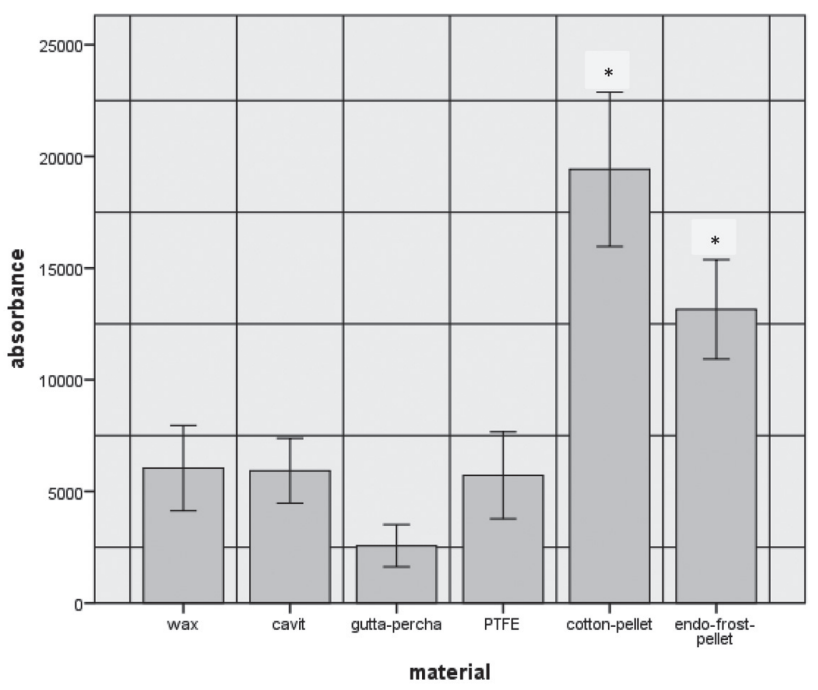

Fig. 6 Fungal adhesion (no units) of C. albicans on different materials (mean, standard deviation).

38.320. Wax $(4,010)$, cavit $(3,900)$, gutta-percha $(4,110)$, and PTFE $(8,880)$ showed significantly $(p<0.001)$ lower fluorescence intensities than endo-frost pellets $(20,710)$ and cotton pellets $(38,320)$. The relative fluorescence intensities measured for the other materials did not show any significant differences $(p>0.05)$.

\section{Candida albicans}

After Candida albicans proliferation, relative luminescence intensities (no units) differed significantly $(p<0.001)$, indicating different fungal proliferation quantities of the investigated dental materials (Fig. 6).
The significantly $(p<0.001)$ lowest median fluorescence intensity was found for gutta-percha $(2,567)$. Moderate values were found for wax $(6,045)$, cavit $(5,923)$, and PTFE $(5,720)$. Cotton pellets $(19,420)$ and endo-frost pellets $(13,154)$ showed the significantly $(p<0.001)$ highest relative fluorescence intensities of all materials.

\section{DISCUSSION}

The results of this present study support the hypothesis that materials for sealing the screw access channel differ in their susceptibility to adhere to streptococcal bacteria and candida species. Within the limitations of an in vitro study, wax, gutta-percha, cavit, and PTFE may be suggested as material of choice for screw access sealing because of their significantly lower potential of bacterial and fungal adhesion. Currently, various materials are used for filling the access hole before the cementation of a crown or after the insertion of a hybrid abutment crown, but most dentists prefer endofrost pellets and cotton pellets because of their easier retrievability ${ }^{1-3,16}$.

Differences in surface roughness and surface free energy are the major reasons some materials are more prone to bacterial and fungal adherence than others ${ }^{34,35)}$. It is generally recognized that rough surfaces on implants or dental materials support bacterial and fungal adherence and retention of biofilms ${ }^{31,36)}$. Furthermore, it is well known that grooves and pits are responsible for initial bacterial attachment and the protection of bacteria from shear forces ${ }^{36}$. In contrast to this laboratory situation, the process of biofilm formation on surfaces within the oral cavity is influenced by multiple collateral parameters including coadhasion to other microbial species, presence of the acquired pellicle and the shear force of the floating saliva ${ }^{31,37}$. To ensure a test model as simple as possible and reduce influences on bacterial and fungal adherence to material properties only, no acquired pellicle was used in this study. However, a multi-species biofilm model including Streptococcus oralis, Streptococcus mutans, and Candida albicans was used to guarantee the clinical relevance of microbial adhesion testing.

In condensable materials, bacterial and fungal ${ }^{38)}$ adherence are to be expected due to microleakage effects that may be caused by polymerization shrinkage or inadequate adhesion to the walls of the screw access channel. In all tests, condensable materials showed the lowest adhesion of microorganisms, and cotton pellets and endo-frost pellets the highest adhesion. This finding could be attributed to the untextured fiber structure of the pellets that may easily entrap microorganisms. Although sterilizable, the surface texture may further support re-contamination during clinical application. PTFE resulted in distinctly reduced adhesion despite its fiber structure ${ }^{38,39}$. The thermoplastic polyhalogenolefine shows extremely low surface-free energy, resulting in smooth and inert material surfaces that impede bacterial adhesion ${ }^{16,39)}$. Therefore, PTFE showed low adhesion in the range 
of condensable materials. The fact that PTFE is also sterilizable and easy to remove if necessary seems advantageous in clinical application.

Up to now, the quantity of bacteria initially colonizing the intra-implant cavitiy has not been fully investigated. Under clincial conditions, mikroleakage effects, induced by thermal changes might lead to a further uncontrolled increase of number and type of bacteria in the screw channel. No aging procedures such as thermal cycling was performed because this study aimed to differentiate between individual materials and therefore required consistent conditions to allow homogeneous growth of bacteria and candida.

Most studies investigating biofilms on implant surfaces aim at external bacterial contamination on restorations, abutments, and implant surfaces. The possibility of leakage of bacteria or endotoxin in the implant-abutment interface has been shown in multiple in vitro trials, stressing the importance of studying internal bacteria contamination of implant cavities ${ }^{40-42}$. These investigations were performed in vitro under static conditions and without any suprastructures. However, functional loading of clinical restorations may be an important factor for bacterial infiltration of the intra-implant cavity ${ }^{43)}$. Leakage is a major cause for inflammatory reactions at the implant-abutment interface, resulting in oral malodor, inflammation and marginal bone loss ${ }^{44)}$. Two-component implant systems present gaps at the implant-abutment connection and the screw hole, leading to entrapment of food particels, bacteria and fungi. Adhesion of microorganisms may cause initial marginal bone loss after one year of functional loading ${ }^{45,46)}$. During prosthetic rehabilitation, microbial internal contamination of the implant body with gram-positive bacteria, including streptococci and facultative and anaerobic rods, is nearly unavoidable ${ }^{18,47)}$. Assessment of bacterial and fungal adhesion is one of the characteristics that may be correlated to clinical performance and should be taken into consideration when selecting the material for sealing the screw access channel. In contrast to in vitro investigations, bacterial and fungal adhesion to any surface within the oral cavity is influenced by the compound of saliva, co-adhesion to other bacterial or fungal species and the formation of the acquired pellicle ${ }^{37}$. As bacteria and cadida adherence in the oral cavity is a very complex process, it is clear that the findings of this investigation cannot be completely transferred to a clinical situation. However, the aim of this study was the differentiation between sealing materials, which seems easier with a standardized environment. Stable environmental conditions are required for bacterial/candida growth and differentiation between the materials. In this laboratory study only gram-postive bacteria were included, despite the fact that gram-negative microorganisms are mainly involved in the etiology and pathogenesis of peri-implantitis ${ }^{6}$. With regard to this aspect, future studies might inlcude gram-negative bacteria and set their focus on in vivo study settings to confirm the clinical feasibility of the results of this trial. Improved understanding of the presence of oral pathogens at the peri-implant sulci may lead to the development of dental materials with lower susceptibility to adhere to oral bacteria or fungi.

\section{CONCLUSIONS}

The screw channel of implant-suported restorations represents a bacterial and fungal reservoir. Within the limitations of this simplified in vitro model, the following conclusions can be drawn:

1. The quantity of bacterial and fungal adhesion differed significantly between the assessed dental materials.

2. Sealing the screw channel with cotton and endofrost pellets is ineffective because of their higher potential of bacterial and fungal adhesion.

3. Wax, gutta-percha, cavit, and PTFE may be suggested as the materials of choice for sealing the screw access channel because of their significantly lower potential of bacterial and fungal adhesion.

Efforts should aim at performing controlled in vivo studies to confirm the clinical feasibility of the findings of this study.

\section{REFERENCES}

1) Moraguez OD, Belser UC. The use of polytetrafluoroethylene tape for the management of screw access channels in implantsupported prostheses. J Prosthet Dent 2010; 103: 189-191.

2) Taylor RC, Ghoneim AS, McGlumphy EA. An esthetic technique to fill screw-retained fixed prostheses. J Oral Implantol 2004; 30: 384-385.

3) Weininger B, McGlumphy E, Beck M. Esthetic evaluation of materials used to fill access holes of screw-retained implant crowns. J Oral Implantol 2008; 34: 145-149.

4) Chu KM, Tredwin CJ, Setchell DJ, Hems E. Effect of screw hole filling on retention of implant crowns. Eur J Prosthodont Restor Dent 2005; 13: 154-158.

5) Emms M, Tredwin CJ, Setchell DJ, Moles DR. The effects of abutment wall height, platform size, and screw access channel filling method on resistance to dislodgement of cementretained, implant-supported restorations. J Prosthodont 2007; 16: 3-9.

6) Mombelli A, Decaillet F. The characteristics of biofilms in peri-implant disease. J Clin Periodontol 2011; 38: 203-213.

7) Lindhe J, Meyle J, Periodontology EW. Peri-implant diseases: Consensus report of the sixth european workshop on periodontology. J Clin Periodontol 2008; 35: 282-285.

8) Ericsson I, Persson LG, Berglundh T, Marinello CP, Lindhe $J$, Klinge B. Different types of inflammatory reactions in periimplant soft tissues. J Clin Periodontol 1995; 22: 255-261.

9) Aloise JP, Curcio R, Laporta MZ, Rossi L, da Silva AM, Rapoport A. Microbial leakage through the implant-abutment interface of Morse taper implants in vitro. Clin Oral Implants Res 2010; 21: 328-335.

10) Piattelli A, Scarano A, Paolantonio M, Assenza B, Leghissa GC, Di Bonaventura G, Catamo G, Piccolomini R. Fluids and microbial penetration in the internal part of cement-retained versus screw-retained implant-abutment connections. J Periodontol 2001; 72: 1146-1150.

11) Jansen VK, Conrads G, Richter EJ. Microbial leakage and marginal fit of the implant-abutment interface. Int J Oral Maxillofac Implants 1997; 12: 527-540.

12) Paolantonio M, Perinetti G, D'Ercole S, Graziani F, Catamo G, Sammartino G, Piccolomini R. Internal decontamination of 
dental implants: an in vivo randomized microbiologic 6-month trial on the effects of a chlorhexidine gel. J Periodontol 2008; 79: 1419-1425.

13) Lindhe J, Berglundh T, Ericsson I, Liljenberg B, Marinello C. Experimental breakdown of peri-implant and periodontal tissues. A study in the beagle dog. Clin Oral Implants Res 1992; 3: 9-16.

14) Pontoriero R, Tonelli MP, Carnevale G, Mombelli A, Nyman SR, Lang NP. Experimentally induced peri-implant mucositis. A clinical study in humans. Clin Oral Implants Res 1994; 5: 254-259.

15) Jervoe-Storm PM, Jepsen S, Johren P, Mericske-Stern R, Enkling N. Internal bacterial colonization of implants: association with peri-implant bone loss. Clin Oral Implants Res 2015; 26: 957-963.

16) Cakan U, Gultekin P, Guncu MB, Canay S. Effect of screw access channel filling materials on uniaxial retentive force of cement-retained implant restorations. Aust Dent J 2014; 59: 65-69.

17) Cavalcanti AG, Fonseca FT, Zago CD, Brito Junior RB, Franca FM. Efficacy of gutta-percha and polytetrafluoroethylene tape to microbiologically seal the screw access channel of different prosthetic implant abutments. Clin Implant Dent Relat Res 2016; 18: 778-787.

18) Persson LG, Lekholm U, Leonhardt A, Dahlen G, Lindhe J. Bacterial colonization on internal surfaces of Branemark system implant components. Clin Oral Implants Res 1996; 7: 90-95.

19) Callan DP, Cobb CM, Williams KB. DNA probe identification of bacteria colonizing internal surfaces of the implantabutment interface: a preliminary study. J Periodontol 2005; 76: $115-120$.

20) Augthun M, Conrads G. Microbial findings of deep periimplant bone defects. Int J Oral Maxillofac Implants 1997; 12: $106-112$

21) Iha K, Suzuki N, Yoneda M, Takeshita T, Hirofuji T. Effect of mouth cleaning with hinokitiol-containing gel on oral malodor: a randomized, open-label pilot study. Oral Surg Oral Med Oral Pathol Oral Radiol 2013; 116: 433-439.

22) Scully C, Porter S, Greenman J. What to do about halitosis. BMJ 1994; 308: 217-218.

23) Sterer N, Rosenberg M. Effect of deglycosylation of salivary glycoproteins on oral malodour production. Int Dent J 2002; 52 Suppl 3: 229-232.

24) Winkel EG, Roldan S, Van Winkelhoff AJ, Herrera D, Sanz M. Clinical effects of a new mouthrinse containing chlorhexidine, cetylpyridinium chloride and zinc-lactate on oral halitosis. A dual-center, double-blind placebo-controlled study. J Clin Periodontol 2003; 30: 300-306.

25) Metwalli KH, Khan SA, Krom BP, Jabra-Rizk MA. Streptococcus mutans, Candida albicans, and the human mouth: a sticky situation. PLoS Pathog 2013; 9: e1003616.

26) Koga C, Yoneda M, Nakayama K, Yokoue S, Haraga M, Oie T, Suga A, Okada F, Matsuura H, Tsue F, Suzuki N, Hirofuji T. The detection of Candida species in patients with halitosis. Int J Dent 2014; 2014: 857647.

27) Verran J. Malodour in denture wearers: an ill-defined problem. Oral Dis 2005; 11 Suppl 1: 24-28.

28) Rimondini L, Marin C, Brunella F, Fini M. Internal contamination of a 2-component implant system after occlusal loading and provisionally luted reconstruction with or without a washer device. J Periodontol 2001; 72: 1652-1657.

29) Cosyn J, Van Aelst L, Collaert B, Persson GR, De Bruyn H. The peri-implant sulcus compared with internal implant and suprastructure components: a microbiological analysis. Clin Implant Dent Relat Res 2011; 13: 286-295.
30) Abdulwahhab SS. High-impact strength acrylic denture base material processed by autoclave. J Prosthodont Res 2013; 57: 288-293.

31) Buergers R, Rosentritt M, Handel G. Bacterial adhesion of Streptococcus mutans to provisional fixed prosthodontic material. J Prosthet Dent 2007; 98: 461-469.

32) O'Brien J, Wilson I, Orton T, Pognan F. Investigation of the Alamar Blue (resazurin) fluorescent dye for the assessment of mammalian cell cytotoxicity. Eur J Biochem 2000; 267: 54215426.

33) Hahnel S, Rosentritt M, Handel G, Burgers R. In vitro evaluation of artificial ageing on surface properties and early Candida albicans adhesion to prosthetic resins. J Mater Sci Mater Med 2009; 20: 249-255.

34) Quirynen M, Bollen CM. The influence of surface roughness and surface-free energy on supra- and subgingival plaque formation in man. A review of the literature. J Clin Periodontol 1995; 22: 1-14.

35) Sardin S, Morrier JJ, Benay G, Barsotti O. In vitro streptococcal adherence on prosthetic and implant materials. Interactions with physicochemical surface properties. J Oral Rehabil 2004; 31: 140-148.

36) Teughels W, Van Assche N, Sliepen I, Quirynen M. Effect of material characteristics and/or surface topography on biofilm development. Clin Oral Implants Res 2006; 17 Suppl 2: 68-81.

37) Whittaker CJ, Klier CM, Kolenbrander PE. Mechanisms of adhesion by oral bacteria. Annu Rev Microbiol 1996; 50: 513552.

38) Hess TA.A technique to eliminate subgingival cement adhesion to implant abutments by using polytetrafluoroethylene tape. J Prosthet Dent 2014; 112: 365-368.

39) Elter C, Heuer W, Demling A, Hannig M, Heidenblut T, Stiesch M. Comparative analysis of biofilm formation on dental implant abutments with respect to supra- and subgingival areas: Polytetrafluoroethylene versus titanium. Int J Prosthodont 2011; 24: 373-375.

40) Harder S, Quabius ES, Ossenkop L, Kern M. Assessment of lipopolysaccharide microleakage at conical implant-abutment connections. Clin Oral Investig 2012; 16: 1377-1384.

41) Koutouzis T, Wallet S, Calderon N, Lundgren T. Bacterial colonization of the implant-abutment interface using an in vitro dynamic loading model. J Periodontol 2011; 82: 613-618.

42) Harder S, Dimaczek B, Acil Y, Terheyden H, Freitag-Wolf S, Kern M. Molecular leakage at implant-abutment connection -in vitro investigation of tightness of internal conical implant-abutment connections against endotoxin penetration. Clin Oral Investig 2010; 14: 427-432.

43) Steinebrunner L, Wolfart S, Bossmann K, Kern M. In vitro evaluation of bacterial leakage along the implant-abutment interface of different implant systems. Int J Oral Maxillofac Implants 2005; 20: 875-881.

44) Berberi A, Tehini G, Rifai K, Bou Nasser Eddine F, Badran B, $\mathrm{Akl} \mathrm{H}$. Leakage evaluation of original and compatible implantabutment connections: In vitro study using Rhodamine B. J Dent Biomech 2014; 5: 1758736014547143.

45) Broggini N, McManus LM, Hermann JS, Medina RU, Oates TW, Schenk RK, Buser D, Mellonig JT, Cochran DL. Persistent acute inflammation at the implant-abutment interface. J Dent Res 2003; 82: 232-237.

46) Adell R, Lekholm U, Rockler B, Branemark PI, Lindhe J, Eriksson B, Sbordone L. Marginal tissue reactions at osseointegrated titanium fixtures (I). A 3-year longitudinal prospective study. Int J Oral Maxillofac Surg 1986; 15: 39-52.

47) Keller W, Bragger U, Mombelli A. Peri-implant microflora of implants with cemented and screw retained suprastructures. Clin Oral Implants Res 1998; 9: 209-217. 